\title{
Growth of Silver Nanoparticles by DC Magnetron Sputtering
}

\author{
P. Asanithi, ${ }^{1}$ S. Chaiyakun, ${ }^{2,3}$ and P. Limsuwan ${ }^{1,3}$ \\ ${ }^{1}$ Applied Nanotechnology Laboratory (ANT Lab), Department of Physics, King Mongkut's University of Technology Thonburi, \\ Bangkok 10140, Thailand \\ ${ }^{2}$ Department of Physics, Faculty of Science, Burapha University, Chonburi 20131, Thailand \\ ${ }^{3}$ Thailand Center of Excellence in Physics, CHE, Ministry of Education, Bangkok 10400, Thailand
}

Correspondence should be addressed to P. Asanithi, asanithi@hotmail.com

Received 13 May 2012; Accepted 27 June 2012

Academic Editor: Zhenhui Kang

Copyright ( $\odot 2012$ P. Asanithi et al. This is an open access article distributed under the Creative Commons Attribution License, which permits unrestricted use, distribution, and reproduction in any medium, provided the original work is properly cited.

Silver (Ag) nanoparticles are of great interest for many applications. However, their fabrications have been limited by the synthesis methods in which size, shape, and aggregation are still difficult to control. Here, we reported on using direct current (DC) magnetron sputtering for growing Ag nanoparticles on unheated substrates. Effects of sputtering condition on grain size of $\mathrm{Ag}$ nanoparticle were discussed. At constant sputtering current and deposition time, the average sizes of Ag nanoparticles were $5.9 \pm$ $1.8,5.4 \pm 1.3$, and $3.8 \pm 0.7 \mathrm{~nm}$ for the target-substrate distances of 10,15 , and $20 \mathrm{~cm}$, respectively. The morphology evolution from nanoparticles to wormlike networks was also reported. High-resolution transmission electron microscopy image represented clear lattice fringes of Ag nanoparticles with a d-spacing of $0.203 \mathrm{~nm}$, corresponding to the (200) plane. The technique could be applied for growth of nanoparticles that were previously difficult to control over size and size uniformity.

\section{Introduction}

Silver (Ag) nanoparticles are reported to be useful for many applications such as antibacterial activities [1], fluorescence [2], catalysis [3], and plasmon-based sensor [4, 5]. The unique physical, optical, and chemical properties of $\mathrm{Ag}$ nanoparticles are originated from their very high surfaceto-volume ratio and the number of atoms in the nanoscale size. A single Ag nanoparticle can offer higher efficiency of plasmon excitation than gold $(\mathrm{Au})$ and copper $(\mathrm{Cu})$ [6]. For $\mathrm{Ag}$ nanoparticles with the sizes of less than $10 \mathrm{~nm}$, they are highly required for biomedical applications, for example, diagnosis and treatment in which urinary excretion and elimination from the living body is possible [7]. Several synthesis techniques have been used to synthesize Ag nanoparticle, including chemical reduction [8], green synthesis [9], laser ablation [10], gamma irradiation [11], electron irradiation [12], thermal decomposition [13], photochemical methods [14], and microwave-assisted synthesis [15]. However, most of them have always struggled with size and shape controllability as well as their aggregation. Therefore, further progress on applications of Ag nanoparticles essentially relies upon the development in synthesis technique to solve such problems.
Direct current (DC) magnetron sputtering has long been used to fabricate thin films, nanostructured coatings, and nanoparticles of various materials, including metallic oxide, nitride, and carbide films [16-22]. Recently, Liu et al. [23] reported on growth of metal nanoparticles, for example, $\mathrm{Au}$ and Ag, using DC sputtering systems. The metal targets were sputtered onto ionic liquids to form self-assembly of metal nanoparticles on carbon supports in the liquid. Thus, DC magnetron sputtering could be a potential technique for synthesizing metal nanoparticles. The technique also reduces the complexity of synthesis processes and facilitates control over size, shape, and aggregation of the nanoparticles [24]. However, little research to date has focused on using this technique to synthesize Ag nanoparticles.

In this study, we optimize the suitable sputtering conditions for growing $\mathrm{Ag}$ nanoparticles with uniform size of less than $10 \mathrm{~nm}$. The technique is based on DC magnetron sputtering of Ag target on silicon wafers and carbon-coated copper grids. Our technique is different from the conventional sputtering techniques in which heating substrate is no longer used. The formation of Ag nanoparticles is investigated under different sputtering conditions including targetsubstrate distance, deposition time, and sputtering current. In addition, wormlike morphology due to coalescence of Ag 


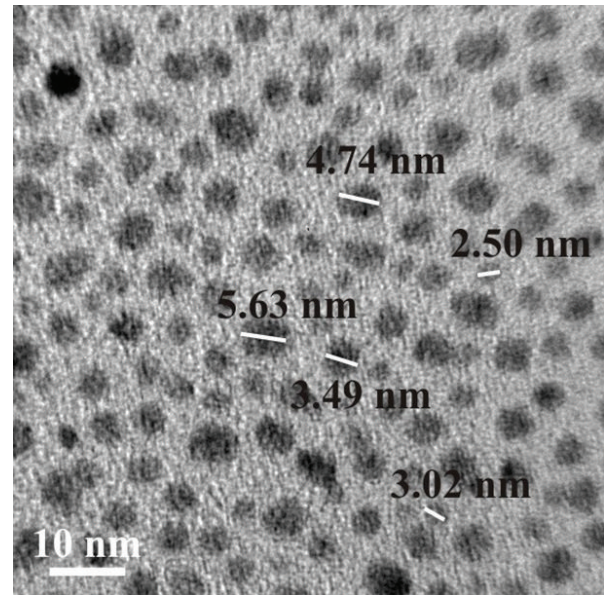

(a)

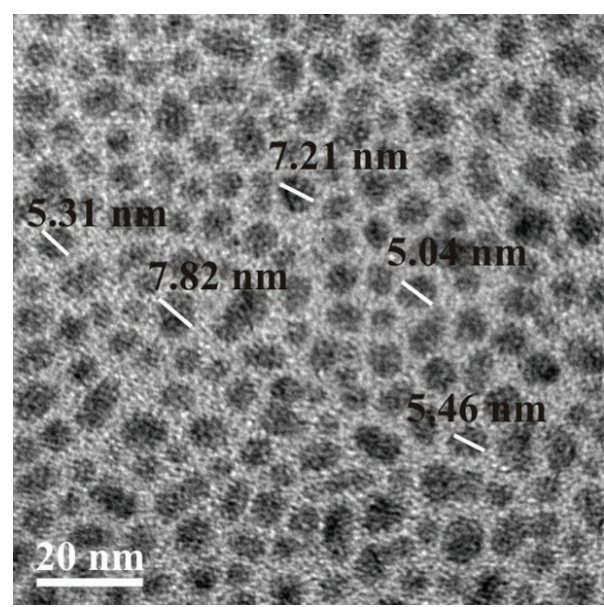

(c)

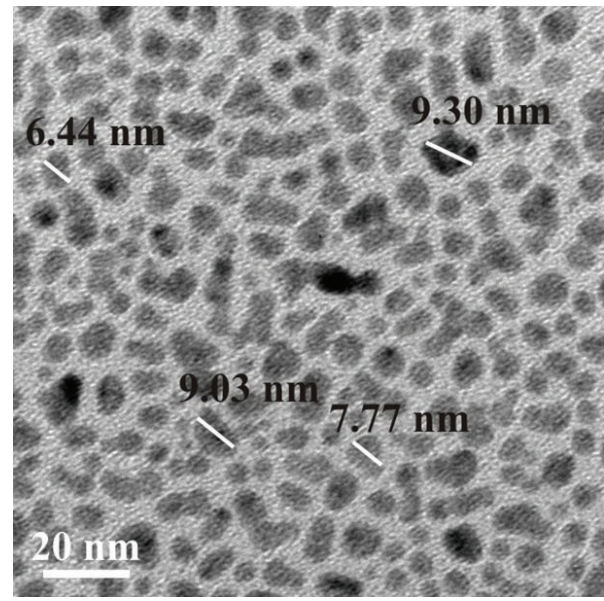

(e)

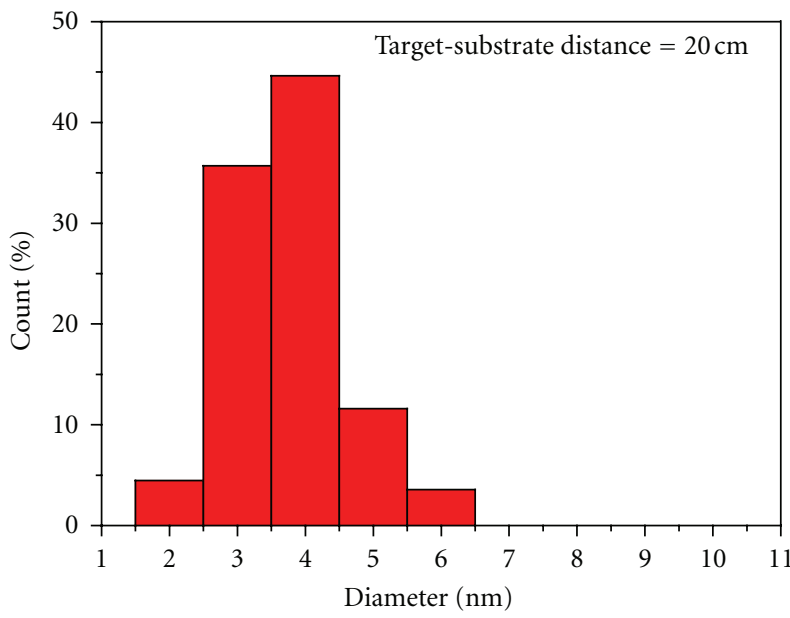

(b)

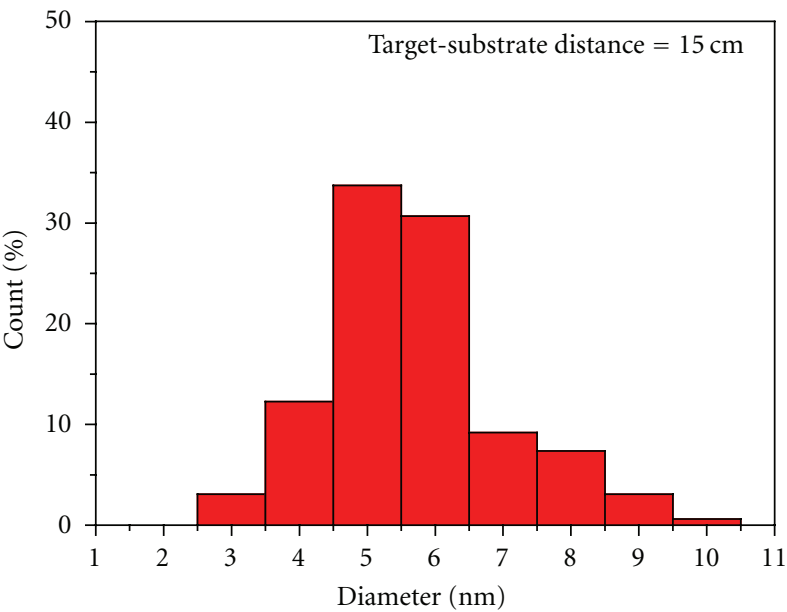

(d)

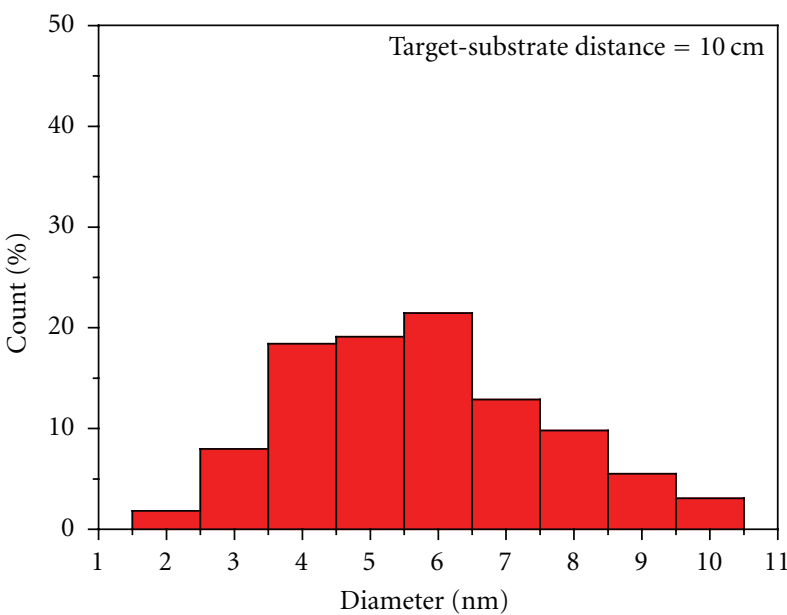

(f)

FIGURE 1: TEM images of silver nanoparticles deposited on carbon-coated copper grid at different target-substrate distances and their plots of particle-size distribution: (a) and (b) $20 \mathrm{~cm}$, (c) and (d) $15 \mathrm{~cm}$, and (e) and (f) $10 \mathrm{~cm}$. The total number of counting particles refers to $100 \%$. Here, 200 particles were used for each plot. 


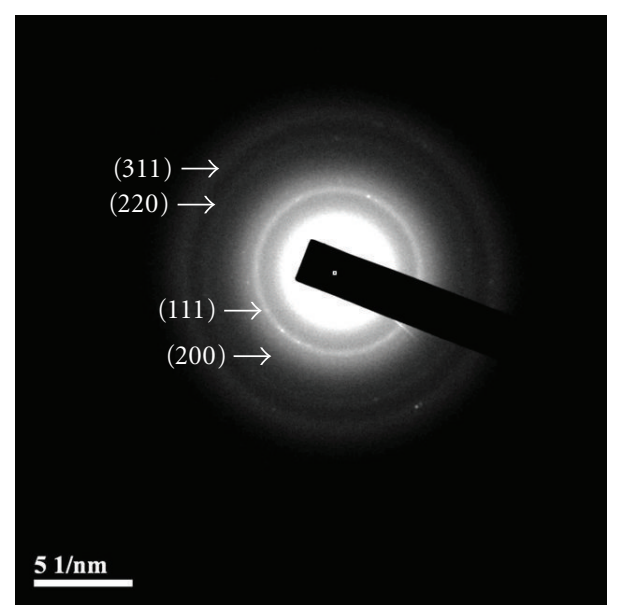

(a)

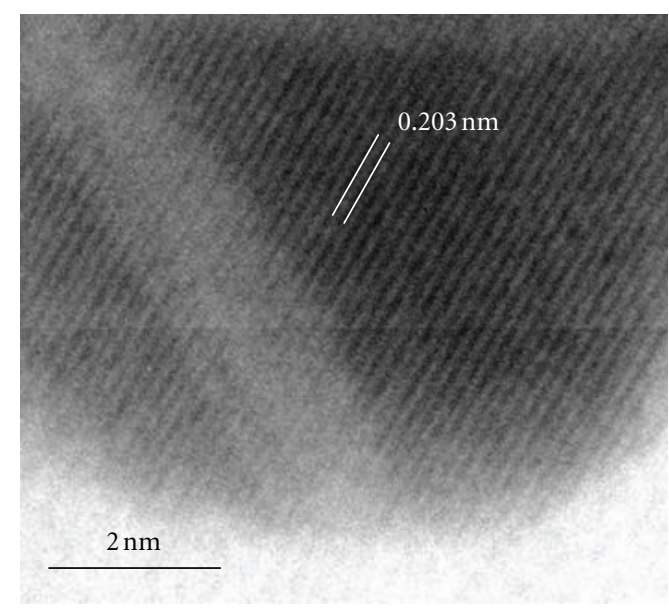

(b)

Figure 2: (a) Selected-area electron diffraction (SAED) of randomly selected Ag nanoparticles; (b) HRTEM image of Ag showing d-spacing for the (200) plane. Both are from the target-substrate distance of $15 \mathrm{~cm}$.

nanoparticles is also reported. The samples are investigated by transmission electron microscopy (TEM) and atomic force microscopy (AFM).

\section{Experimental}

2.1. Material Preparation. Ag nanoparticles were deposited on unheated substrates using a home-built DC-unbalanced magnetron system. The vacuum chamber has a diameter of $31 \mathrm{~cm}$ and a height of $37 \mathrm{~cm}$. Metallic silver with purity of $99.995 \%$ and a diameter of $7.5 \mathrm{~cm}$ was used as a sputtering target. The base pressure of the deposition chamber was about $5 \times 10^{-6}$ mbar. Ultrahigh purity $\operatorname{Ar}(99.999 \%)$ was used as a sputtering gas. The flow rate of Ar was kept at a constant value of 5 standard cubic centimeters per minute $(\mathrm{sccm})$. The discharge was generated by a DC power supply. The sputtering voltage was kept at $350 \mathrm{~V}$. The substrates we used were silicon (100) wafers for surface morphology analysis and carbon-coated copper grids for microstructure analysis by TEM.

The depositions were carried out at two conditions: (i) the sputtering current and deposition time were kept constant at $50 \mathrm{~mA}$ and $1 \mathrm{sec}$, respectively, whereas the targetsubstrate distances were set at 10,15 , and $20 \mathrm{~cm}$ and (ii) the target-substrate distance and deposition time were kept constant at $20 \mathrm{~cm}$ and $2 \mathrm{sec}$, respectively, whereas the sputtering currents were set at 100 and $150 \mathrm{~mA}$.

2.2. Characterization. The crystalline structure and orientation of the nanoparticles deposited on the TEM grids were investigated by transmission electron microscopy (Jeol, JEM-2100) working at $160 \mathrm{kV}$. The surface morphology of the Ag nanoparticles deposited on Si wafer was investigated using atomic force microscopy (AFM, Digital Instruments, NanoScope III) in a tapping mode.

\section{Results and Discussion}

3.1. Effect of Target-Substrate Distance on the Formation of Silver Nanoparticle. Figures 1(a), 1(c), and 1(d) show TEM images of Ag nanoparticles deposited by the sputtering current of $50 \mathrm{~mA}$ and deposition time of $1 \mathrm{sec}$, but difference in target-substrate distances: 10,15 , and $20 \mathrm{~cm}$. The particle sizes of $200 \mathrm{Ag}$ nanoparticles in Figures 1(a), 1(c), and 1 (e) were analysed, and the particle-size distribution was obtained. The plots of particle-size distribution are shown in Figures 1(b), 1(d), and 1(f). Here, the total number of counting particles refers to $100 \%$. The target-substrate distance had a pronounced effect on grain size of $\mathrm{Ag}$ nanoparticles. The smallest grain size $(3.8 \pm 0.7 \mathrm{~nm})$ with very high size uniformity was obtained from the target-substrate distances of $20 \mathrm{~cm}$ (Figures 1(a) and 1(b)). However, with decreasing the target-substrate distances, the grain size increased while size uniformity decreased. They were $5.4 \pm$ $1.3 \mathrm{~nm}$ (Figures $1(\mathrm{c})$ and $1(\mathrm{~d})$ ) and $5.9 \pm 1.8 \mathrm{~nm}$ (Figures $1(\mathrm{e})$ and $1(\mathrm{f})$ ) for the target-substrate distances of 15 and $10 \mathrm{~cm}$, respectively. Increase in the Ag nanoparticle size when decreasing the target-substrate distance has probably resulted from the increase in total amount of deposited Ag. For example, the shorter the target-substrate distance, the higher the total amount of deposited Ag, and, thus, the larger the $\mathrm{Ag}$ nanoparticle size will be.

Moreover, the target-substrate distance also affected the shape and the distribution of particle's position of $\mathrm{Ag}$ nanoparticle. Ag nanoparticles with the uniform in the distribution of particle's position were clearly observed from the target-substrate distance of $20 \mathrm{~cm}$ (Figure 1(a)). However, for a shorter distance, for example, $15 \mathrm{~cm}$, the shapes of Ag nanoparticle were relatively mixed between spherical and oval shapes (Figures 1(c) and 1(d)). Here, the distribution of particle's position was relatively nonuniform. Thus, from these results, the optimum substrate-target distance for synthesizing $\mathrm{Ag}$ nanoparticles of uniform size is $20 \mathrm{~cm}$. The hypothesis that could account for these phenomena 


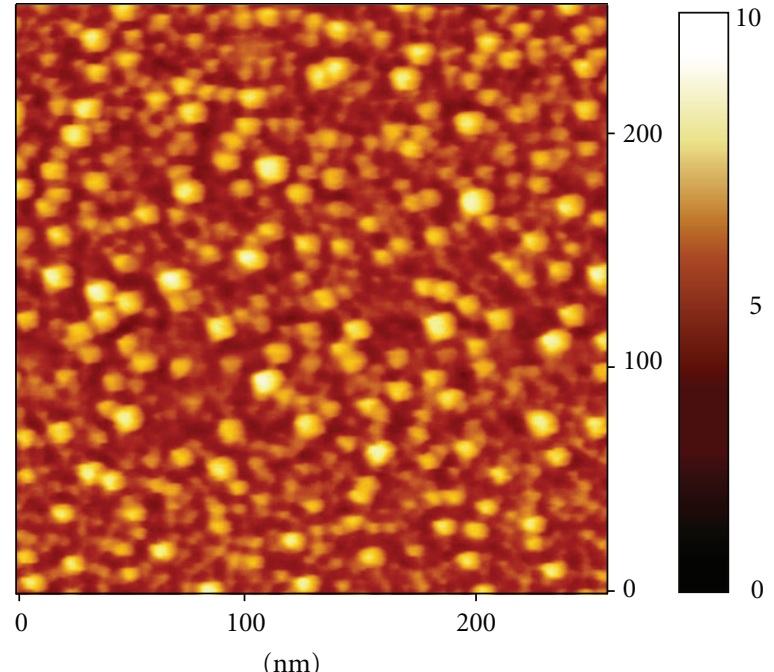

(a)

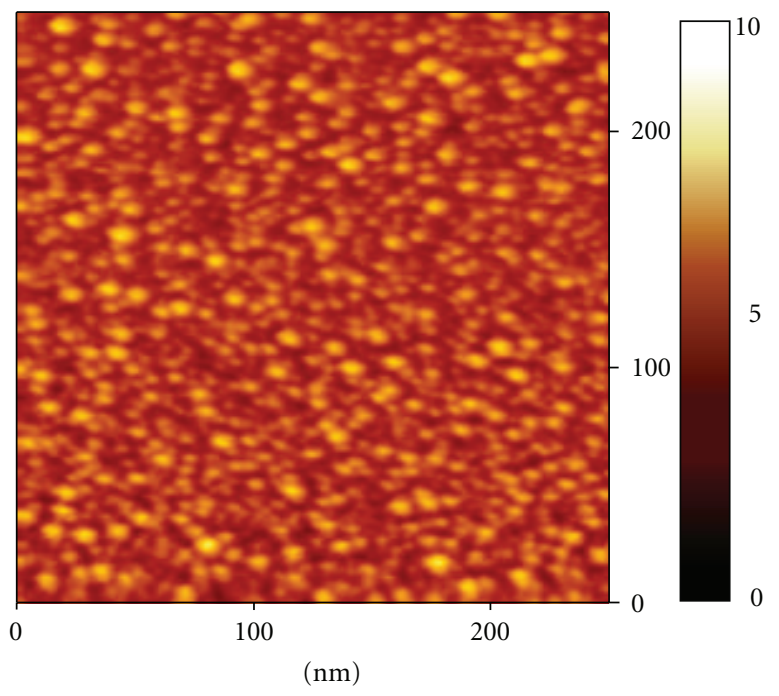

(c)

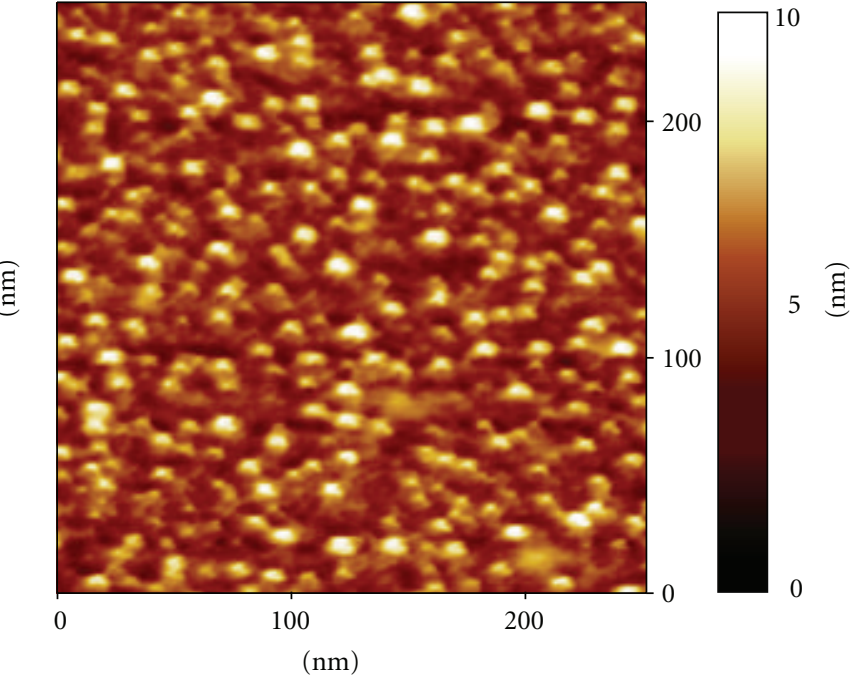

(b)

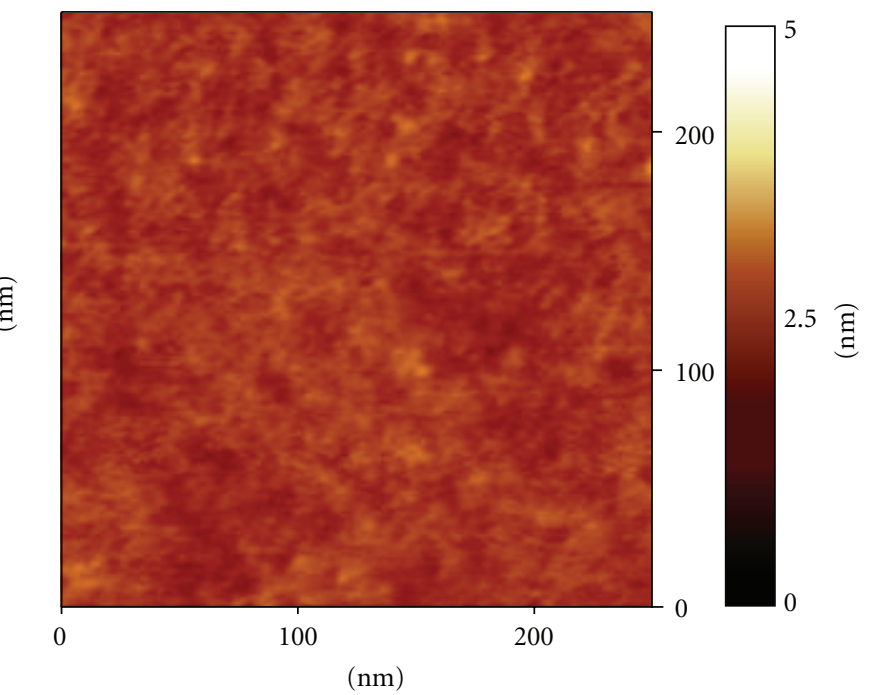

(d)

Figure 3: AFM height images $(250 \mathrm{~nm} \times 250 \mathrm{~nm})$ of Ag nanoparticles deposited on Si substrate at different target-substrate distances: (a) $10 \mathrm{~cm}$, (b) $15 \mathrm{~cm}$, and (c) $20 \mathrm{~cm}$. (d) is AFM height image of bare Si substrate.

is that changing the target-substrate distance affects the deposition rate of $\mathrm{Ag}$ atoms, that is, decreasing in targetsubstrate distance increases the deposition rate. Hence, Ag nanoparticles could grow faster and be larger for the shorter distance. Also, at the high deposition rate, Ag atoms do not have much time to arrange themselves in a good order. This consequently leads to nonuniform in size, shape, and distribution of particle's position.

Figure 2(a) shows the typical results of selected-area electron diffraction (SAED) pattern of Ag nanoparticles deposited at the target-substrate distance of $15 \mathrm{~cm}$. The ring patterns are assigned to the diffraction from the (111), (200), (220), and (311) planes of the face-centered cubic (fcc) structure of silver according to the JCPDS File number 04$0783[25,26]$. Similar SAED patterns for those deposited at other distances are also observed. Figure 2(b) shows the typical HRTEM image representing crystalline structure with a d-spacing of $0.203 \mathrm{~nm}$. This matches with the (200) planes of spherical Ag nanoparticles [26, 27].

The number of Ag atoms in the nanoparticle is estimated since at the nanoscale the number of atoms, especially at the surface, has played an important role on its unique properties. For Ag nanoparticle with an average diameter of $3.8 \mathrm{~nm}$, there are approximately 1,714 atoms of $\mathrm{Ag}$ and about $1 / 3$ of them is at the surface. The calculation follows the coming equations:

$$
\begin{gathered}
N=\frac{V_{\text {nanoparticle }}}{V_{\text {unit cell }}} \times 4, \\
V_{\text {nanoparticle }}=\frac{4}{3} \pi\left(r^{3}\right),
\end{gathered}
$$




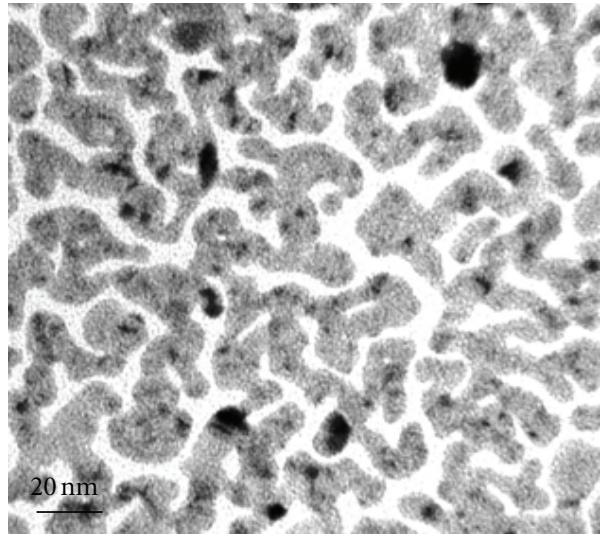

(a)

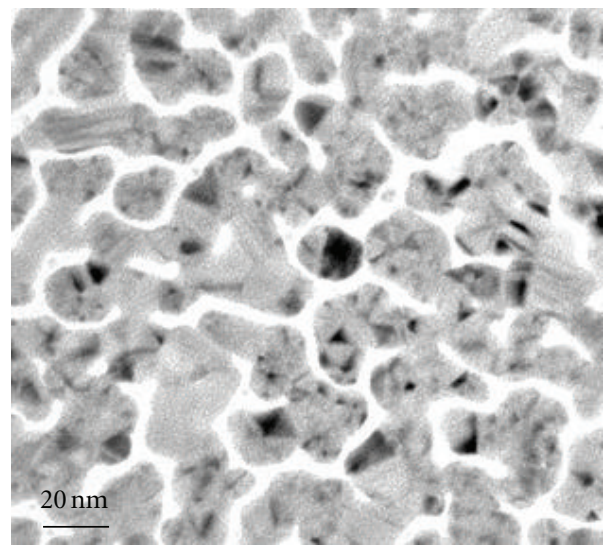

(c)

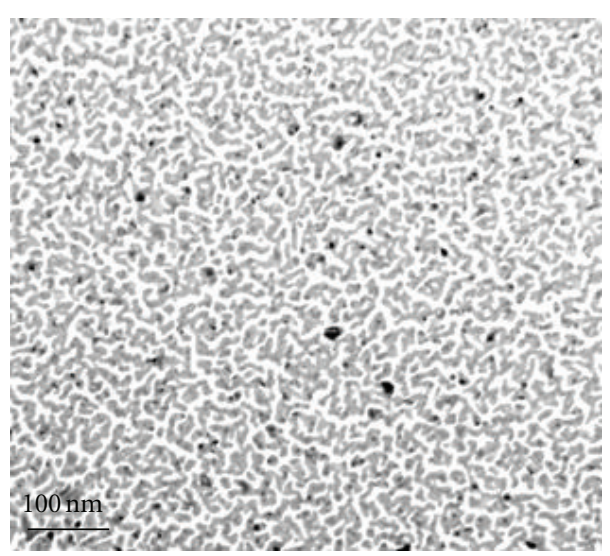

(b)

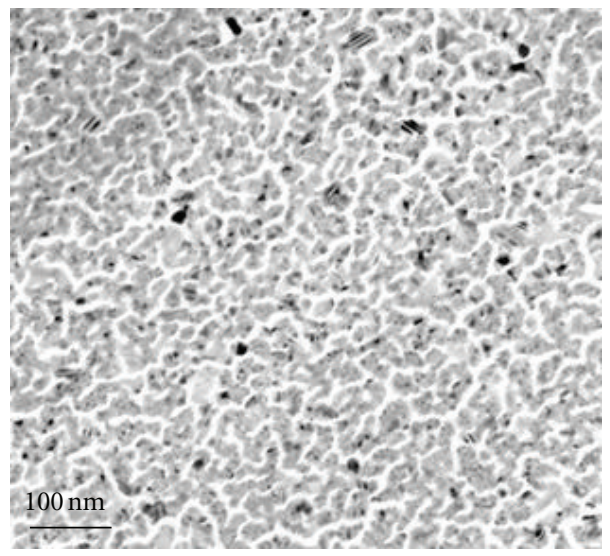

(d)

Figure 4: TEM images of wormlike morphology of Ag deposited on carbon-coated copper grid at different sputtering currents: 100 mA for (a) and (b), and $150 \mathrm{~mA}$ for (c) and (d). All were deposited for $2 \mathrm{sec}$ and $20 \mathrm{~cm}$ of target-substrate distance.

where $N$ is the number of $\mathrm{Ag}$ atoms in the nanoparticle, $V_{\text {nanoparticle }}$ is the volume of Ag nanoparticle, $r$ is the radius of Ag nanoparticle, here with an average diameter of $3.8 \mathrm{~nm}$ $(r=1.9 \mathrm{~nm})$, and $V_{\text {unit cell }}$ is the unit cell volume which is about $0.067 \mathrm{~nm}^{3}$ for Ag. For the fcc structure, there are 4 atoms in a unit cell; thus, the multiplication factor 4 in (1) comes from 4 atoms in the unit cell of fcc structure of silver.

In order to identify the morphology of Ag nanoparticles, AFM of Ag nanoparticles deposited on silicon wafers was carried out. Figures 3(a), 3(b), and 3(c) show AFM height images $(250 \mathrm{~nm} \times 250 \mathrm{~nm})$ of $\mathrm{Ag}$ nanoparticles prepared from the target-substrate distances of 10,15 , and $20 \mathrm{~cm}$, respectively. The particle sizes obtained from AFM height profiles are in good agreement with those observed by TEM images, which are less than $10 \mathrm{~nm}$. Figure $3(\mathrm{~d})$ shows AFM height image of bare Si substrate using in this experiment.

As reported by Sugunan et al. [28] and Kitsomboonloha et al. [29] on controlling the growth and orientation of nanorods by seeding techniques, our Ag nanoparticle synthesized from this technique could be used as a seed for growth of nanowires and nanorods. However, the applications will be left for our future works.
3.2. Effect of Sputtering Current on the Formation of Silver Nanoparticle. From the previous section, at the sputtering current of $50 \mathrm{~mA}$ and deposition time of $1 \mathrm{sec}$, the optimum substrate-target distance for synthesizing $\mathrm{Ag}$ nanoparticles was $20 \mathrm{~cm}$. This condition offered single Ag nanoparticles with the average diameter of $3.8 \mathrm{~nm}$. In this section, further study on the transition in morphology of Ag from nanoparticle to wormlike morphology was carried on. The substratetarget distance was kept constant at $20 \mathrm{~cm}$, but the deposition time was increased from $1 \mathrm{sec}$ to $2 \mathrm{sec}$, and the sputtering current was increased from $50 \mathrm{~mA}$ to 100 and $150 \mathrm{~mA}$, respectively. Ag nanoparticles become coalescence to form wormlike morphology at both sputtering currents of 100 and $150 \mathrm{~mA}$ as shown in Figures 4(a), 4(b), 4(c), and 4(d), respectively. Grain size of wormlike morphology obtained from both conditions is clearly different. Higher sputtering current offers larger grain size of wormlike morphology since the higher sputtering current could increase the total concentration of injected Ag particles and the deposition rate of grain growth [30].

Change in morphology of $\mathrm{Ag}$ from nanoparticle to wormlike morphology (Figure 5) has naturally resulted from the lateral growth of the nanoparticles $[31,32]$. The 


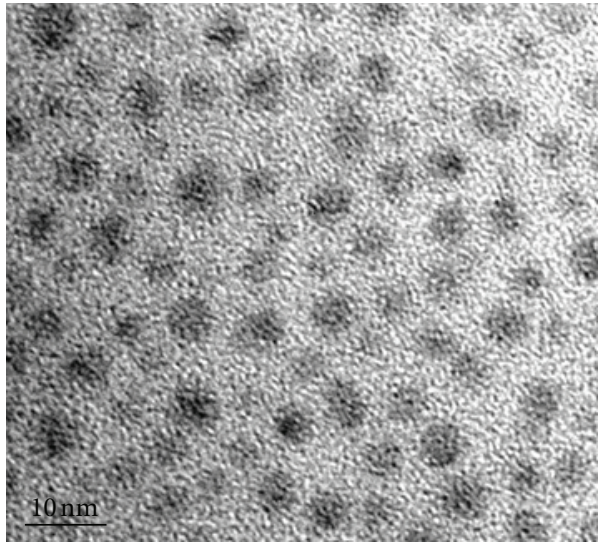

(a)

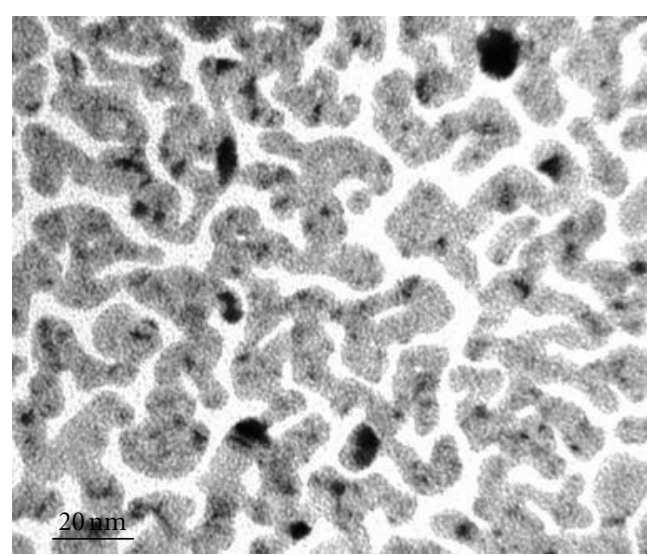

(b)

FIGURE 5: TEM images of Ag representing morphology evolution from (a) nanoparticles in the island stage to (b) wormlike networks in the coalescence stage.

(a)
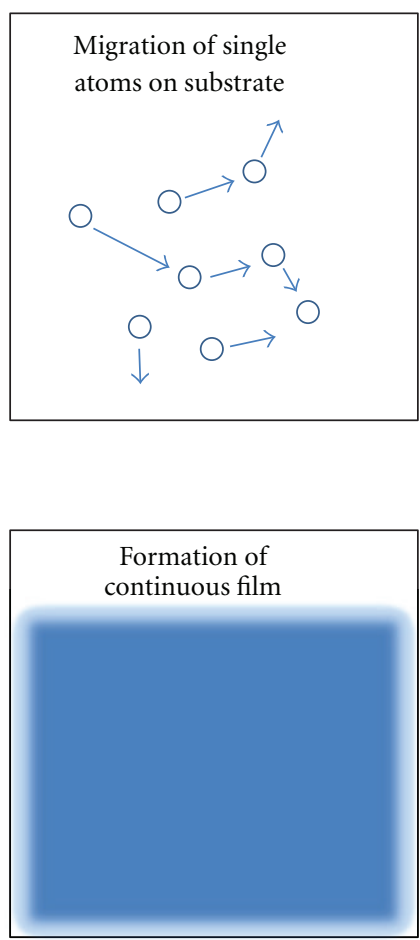

(f) (b)
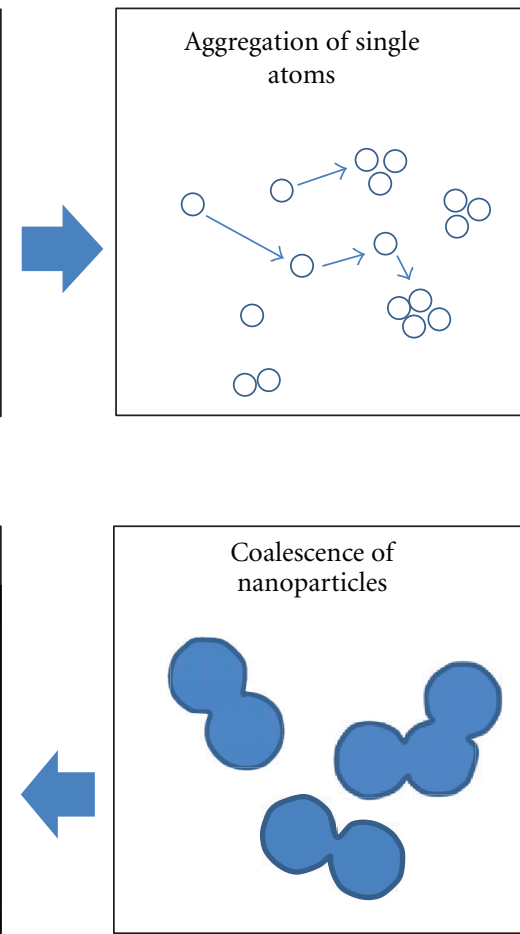

(e) (c)
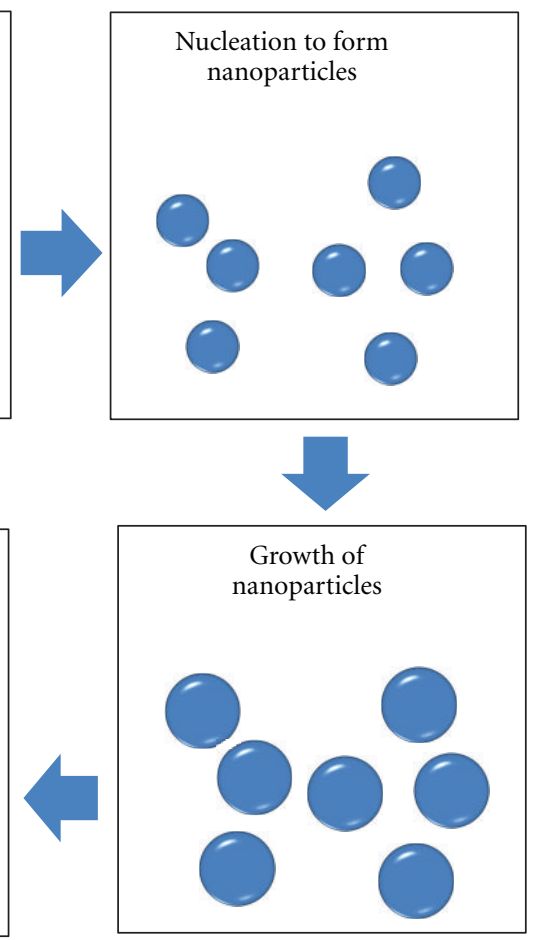

(d)

FIGURE 6: Schematic of thin-film growth based on DC sputtering technique (adapted from [31]). The processes include (a) migration of single atoms on substrate, (b) aggregation of single atoms, (c) nucleation to form nanoparticles, (d) growth of nanoparticles, (e) coalescence of nanoparticles, and (f) formation of continuous film.

mechanisms can be further explained by a fundamental concept of thin film formation, that is, island growth [31]. The processes include (i) migration of single atoms on the substrate surface (Figure 6(a)), (ii) aggregation of the arrival atoms (Figure 6(b)), (iii) nucleation to form nanoparticles (Figure 6(c)), (iv) growth of nanoparticles (Figure 6(d)), (v) coalescence of nanoparticles to form wormlike networks
(Figure 6(e)), and, finally, (vi) formation of continuous film (Figure 6(f)).

Wormlike networks of $\mathrm{Ag}$ atoms could be used as transparent electrodes in flexible electronic devices [33, 34] since the deposition can be prepared at low temperature, as presented in this work, in which heat sensitive substrates, such as polymer substrates, can be used. 


\section{Conclusions}

We have demonstrated that DC magnetron sputtering can be used for synthesizing Ag nanoparticles in which their size can be precisely controlled. At constant sputtering current and deposition time, the size of $\mathrm{Ag}$ nanoparticle is inversely proportional to the target-substrate distance. They were $5.9 \pm 1.8,5.4 \pm 1.3$, and $3.8 \pm 0.7 \mathrm{~nm}$ for the target-substrate distances of 10,15 , and $20 \mathrm{~cm}$, respectively. With the high degree of uniformity in the grain size and position, these Ag nanoparticles could be very interesting for future applications such as catalysts, plasmon-based sensors, and diagnosis and treatment of diseases. Moreover, our demonstration on formation of wormlike networks could lead to further study on fundamental theory and applications of the coalescence process of metallic nanoparticles that takes place on soft materials without heating the substrate.

\section{Acknowledgments}

This work had partially been supported by Thailand Center of Excellence in Physics (ThEP) and King Mongkut's University of Technology Thonburi under The National Research University Project.

\section{References}

[1] M. Guzman, J. Dille, and S. Godet, "Synthesis and antibacterial activity of silver nanoparticles against gram-positive and gram-negative bacteria," Nanomedicine, vol. 8, pp. 37-45, 2012.

[2] H. Xu and K. S. Suslick, "Water-soluble fluorescent silver nanoclusters," Advanced Materials, vol. 22, no. 10, pp. 1078$1082,2010$.

[3] Z. J. Jiang, C. Y. Liu, and L. W. Sun, "Catalytic properties of silver nanoparticles supported on silica spheres," Journal of Physical Chemistry B, vol. 109, no. 5, pp. 1730-1735, 2005.

[4] A. D. McFarland and R. P. Van Duyne, "Single silver nanoparticles as real-time optical sensors with zeptomole sensitivity," Nano Letters, vol. 3, no. 8, pp. 1057-1062, 2003.

[5] E. Filippo, A. Serra, and D. Manno, "Poly(vinyl alcohol) capped silver nanoparticles as localized surface plasmon resonance-based hydrogen peroxide sensor," Sensors and Actuators B, vol. 138, no. 2, pp. 625-630, 2009.

[6] D. D. Evanoff and G. Chumanov, "Synthesis and optical properties of silver nanoparticles and arrays," ChemPhysChem, vol. 6, no. 7, pp. 1221-1231, 2005.

[7] H. Soo Choi, W. Liu, P. Misra et al., "Renal clearance of quantum dots," Nature Biotechnology, vol. 25, no. 10, pp. 1165-1170, 2007.

[8] M. M. Kemp, A. Kumar, S. Mousa et al., "Synthesis of gold and silver nanoparticles stabilized with glycosaminoglycans having distinctive biological activities," Biomacromolecules, vol. 10, no. 3, pp. 589-595, 2009.

[9] P. Raveendran, J. Fu, and S. L. Wallen, "Completely "Green" synthesis and stabilization of metal nanoparticles," Journal of the American Chemical Society, vol. 125, no. 46, pp. 1394013941, 2003.

[10] T. Tsuji, D. H. Thang, Y. Okazaki, M. Nakanishi, Y. Tsuboi, and M. Tsuji, "Preparation of silver nanoparticles by laser ablation in polyvinylpyrrolidone solutions," Applied Surface Science, vol. 254, no. 16, pp. 5224-5230, 2008.

[11] D. Long, G. Wu, and S. Chen, "Preparation of oligochitosan stabilized silver nanoparticles by gamma irradiation," Radiation Physics and Chemistry, vol. 76, no. 7, pp. 1126-1131, 2007.

[12] K. A. Bogle, S. D. Dhole, and V. N. Bhoraskar, "Silver nanoparticles: synthesis and size control by electron irradiation," Nanotechnology, vol. 17, no. 13, article no. 021, pp. 3204-3208, 2006.

[13] H. Gao, L. Liu, Y.-F. Luo, and D.-M. Jia, "In-situ preparation of epoxy/silver nanocomposites by thermal decomposition of silver-imidazole complex," Materials Letters, vol. 65, no. 23-24, pp. 3529-3532, 2011.

[14] K. Mallick, M. J. Witcomb, and M. S. Scurrell, "Polymer stabilized silver nanoparticles: a photochemical synthesis route," Journal of Materials Science, vol. 39, pp. 4459-4463, 2004.

[15] B. Hu, S. B. Wang, K. Wang, M. Zhang, and S. H. Yu, "Microwave-assisted rapid facile "green" synthesis of uniform silver nanoparticles: self-assembly into multilayered films and their optical properties," Journal of Physical Chemistry C, vol. 112, no. 30, pp. 11169-11174, 2008.

[16] I. Safi, "Recent aspects concerning DC reactive magnetron sputtering of thin films: a review," Surface and Coatings Technology, vol. 127, no. 2-3, pp. 203-219, 2000.

[17] C. Ziebert and S. Ulrich, "Hard multilayer coatings containing TiN and/or ZrN: a review and recent progress in their nanoscale characterization," Journal of Vacuum Science and Technology A, vol. 24, no. 3, pp. 554-583, 2006.

[18] P. Taneja, R. Banerjee, P. Ayyub, and G. K. Dey, "Observation of a hexagonal $(4 \mathrm{H})$ phase in nanocrystalline silver," Physical Review B - Condensed Matter and Materials Physics, vol. 64, no. 3, Article ID 033405, pp. 0334051-0334054, 2001.

[19] M. Stueber, H. Holleck, H. Leiste, K. Seemann, S. Ulrich, and C. Ziebert, "Concepts for the design of advanced nanoscale PVD multilayer protective thin films," Journal of Alloys and Compounds, vol. 483, no. 1-2, pp. 321-333, 2009.

[20] F. X. Bock, T. M. Christensen, S. B. Rivers, L. D. Doucette, and R. J. Lad, "Growth and structure of silver and silver oxide thin films on sapphire," Thin Solid Films, vol. 468, no. 1-2, pp. 5764, 2004.

[21] L. A. A. Pettersson and P. G. Snyder, "Preparation and characterization of oxidized silver thin films," Thin Solid Films, vol. 270, no. 1-2, pp. 69-72, 1995.

[22] S. M. Hou, M. Ouyang, H. F. Chen et al., "Fractal structure in the silver oxide thin film," Thin Solid Films, vol. 315, no. 1-2, pp. 322-326, 1998.

[23] C.-H. Liu, B.-H. Mao, J. Gao et al., "Size-controllable selfassembly of metal nanoparticles on carbon nanostructures in room-temperature ionic liquids by simple sputtering deposition," Carbon, vol. 50, no. 8, pp. 3008-3014, 2012.

[24] E. Körner, M. H. Aguirre, G. Fortunato, A. Ritter, J. Rühe, and D. Hegemann, "Formation and distribution of silver nanoparticles in a functional plasma polymer matrix and related Ag+ release properties," Plasma Processes and Polymers, vol. 7, no. 7, pp. 619-625, 2010.

[25] N. Ahmad, S. Sharma, M. K. Alam et al., "Rapid synthesis of silver nanoparticles using dried medicinal plant of basil," Colloids and Surfaces B, vol. 81, no. 1, pp. 81-86, 2010.

[26] Z. Zaheer and Rafiuddin, "Multi-branched flower-like silver nanoparticles: preparation and characterization," Colloids and Surfaces A, vol. 384, no. 1-3, pp. 427-431, 2011.

[27] M. Grouchko, I. Popov, V. Uvarov, S. Magdassi, and A. Kamyshny, "Coalescence of silver nanoparticles at room 
temperature: unusual crystal structure transformation and dendrite formation induced by self-assembly," Langmuir, vol. 25, no. 4, pp. 2501-2503, 2009.

[28] A. Sugunan, H. C. Warad, M. Boman, and J. Dutta, "Zinc oxide nanowires in chemical bath on seeded substrates: role of hexamine," Journal of Sol-Gel Science and Technology, vol. 39, no. 1, pp. 49-56, 2006.

[29] R. Kitsomboonloha, S. Baruah, M. T. Z. Myint, V. Subramanian, and J. Dutta, "Selective growth of zinc oxide nanorods on inkjet printed seed patterns," Journal of Crystal Growth, vol. 311, no. 8, pp. 2352-2358, 2009.

[30] H. Wender, L. F. De Oliveira, P. Migowski et al., "Ionic liquid surface composition controls the size of gold nanoparticles prepared by sputtering deposition," Journal of Physical Chemistry C, vol. 114, no. 27, pp. 11764-11768, 2010.

[31] K. D. Leaver and B. N. Chapman, Thin Films, Wykeham Publications, London, UK, 1971.

[32] A. V. Osipov, "Kinetic model of vapour-deposited thin film condensation: stage of liquid-like coalescence," Thin Solid Films, vol. 261, no. 1-2, pp. 173-182, 1995.

[33] S. De, P. J. King, P. E. Lyons, U. Khan, and J. N. Coleman, "Size effects and the problem with percolation in nanostructured transparent conductors," ACS Nano, vol. 4, no. 12, pp. 7064 7072, 2010.

[34] V. Scardaci, R. Coull, P. E. Lyons, D. Rickard, and J. N. Coleman, "Spray deposition of highly transparent, lowresistance networks of silver nanowires over large areas," Small, vol. 7, no. 18, pp. 2621-2628, 2011. 

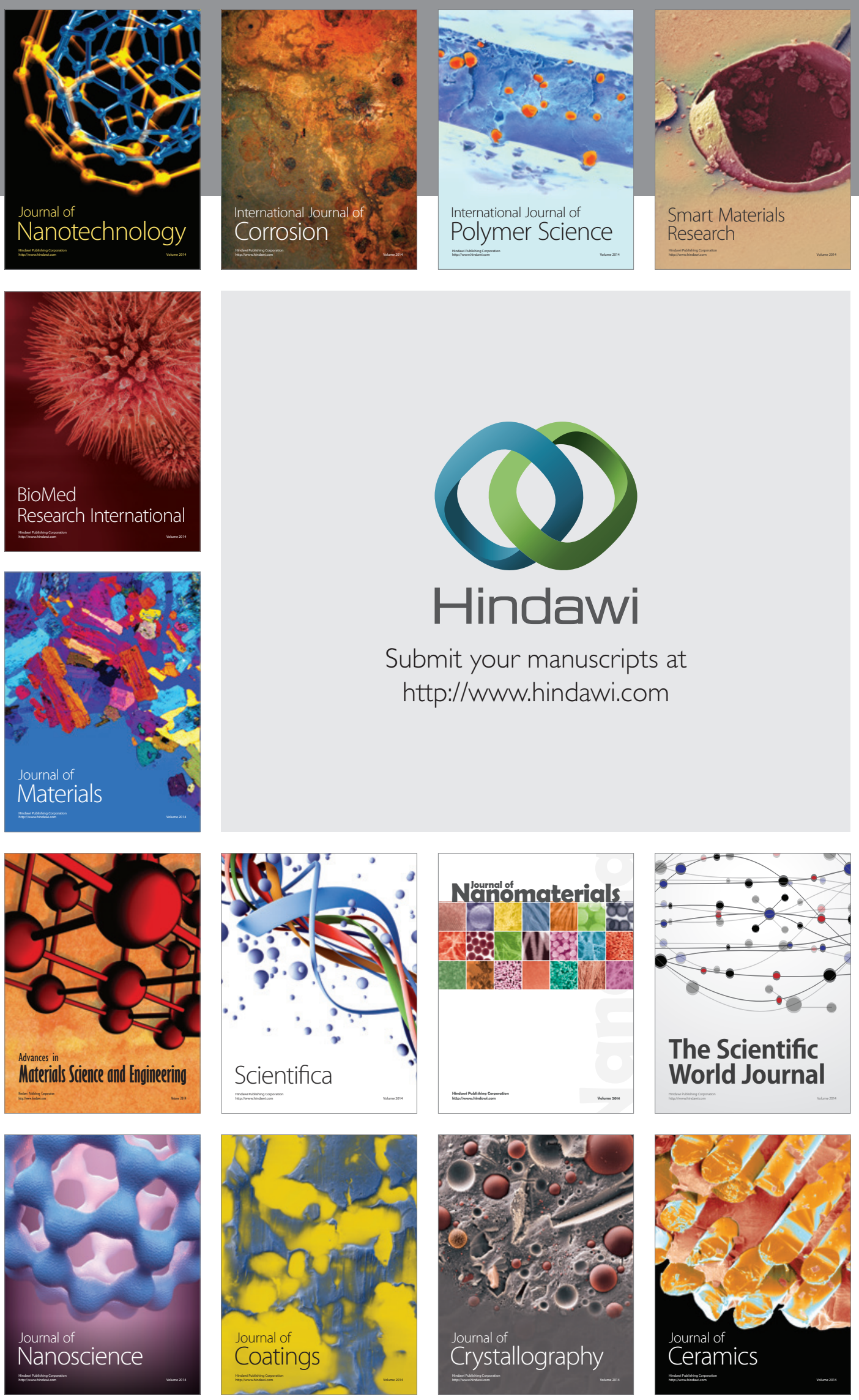

The Scientific World Journal

Submit your manuscripts at

http://www.hindawi.com

\section{World Journal}

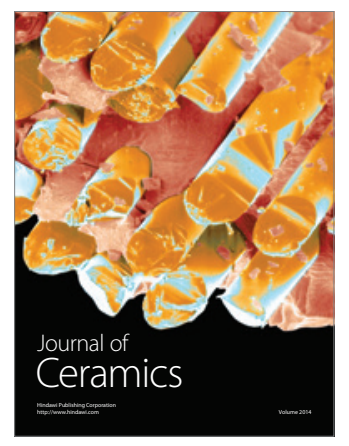

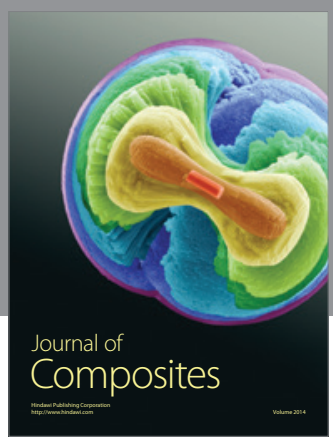
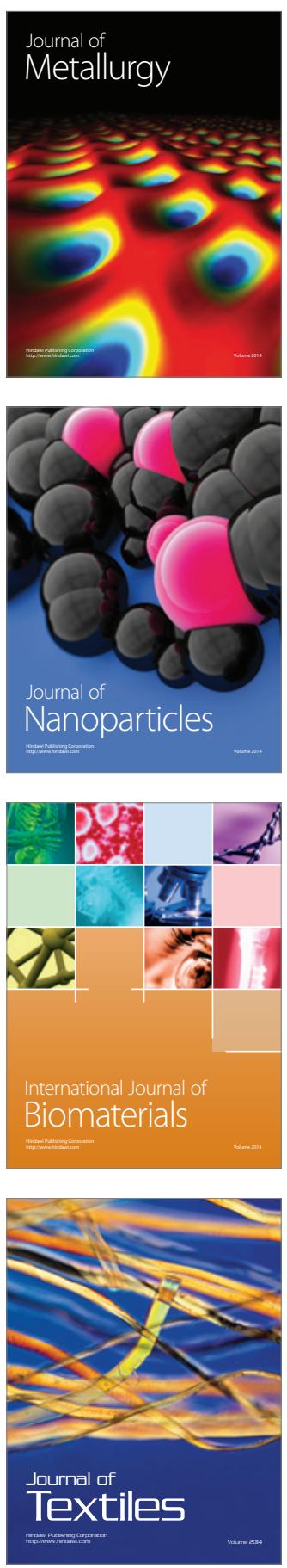